\title{
Neonatal Seizure and Afterward, Epilepsy: A Systematic Review
}

\author{
Ali Zafari', Fatemeh Pajouhandeh ${ }^{2 *([)}$, Mehran Arab Ahmadi $^{3}{ }^{(\bigodot)}$ \\ ${ }^{1}$ Faculty of Medicine, Shahid Beheshti University of Medical Sciences, Tehran, Iran \\ ${ }^{2}$ Department of Neonatology, Tehran Mahdiyeh Hospital, Shahid Beheshti University of Medical Sciences, Tehran, Iran \\ ${ }^{3}$ Functional Neurosurgery Research Center, Shahid Beheshti University of Medical Sciences, Tehran, Iran
}

\begin{abstract}
Background: The purpose of the current study is to estimate the incidence of epilepsy after neonatal seizure (NS) by reviewing of the latest studies on the relationship between NSs and epilepsy in newborns and also discuss risk factors may contribute to this relationship.

Methods: A literature review was performed using the search terms "neonatal seizure AND epilepsy," "newborns AND epilepsy," "postneonatal epilepsy." After exclusion of several studies, which did not meet inclusion criteria, the epilepsy incidence rate was measured by dividing the number of all cases of epilepsy who had a history of NS in selected studies considered with the number of all newborns enrolled to the studies minus the number of cases who lost the follow-ups.

Results: By reviewing the literature, 13 studies were found, which completely meet the inclusion criteria and published between 2009 and 2019, of which three were population-based while the remaining studies performed hospital-based. Overall, the population evaluated in these series has been estimated to be 2438 newborns of which 454 died, and 300 missed the follow-ups. The incidence rate for afterward epilepsy in all 1684 subjects with NS was $20 \%$, literally 343 of the NS subjects.

Conclusion: The presented review enrolled the most recent studies encompassing enough and extended the time as well as adequate sample size. Epilepsy is considered a common outcome of NS, particularly in those with other neurodevelopmental comorbidities, even if there were always several limits associated with various study designs and condition.

Keywords: Newborns; Postneonatal epilepsy; Neonatal seizures; Outcome.
\end{abstract}

Citation: Zafari A, Pajouhandeh F, Arab Ahmadi M. Neonatal seizure and afterward, epilepsy: a systematic review. Int Clin Neurosci J. 2019;6(2):42-45. doi: 10.15171/icnj.2019.09.

\section{Introduction}

To our knowledge, neonatal seizure (NS) accounts for one of the most common acute neurological conditions in many neonatal intensive care units. ${ }^{1}$ There are numerous etiologies may the seizures arise from. ${ }^{2}$ Any acute brain damage by different causes could raise the possibility of NSs. The incidence rate of 1.8 to 3.5 per 1000 birth has been measured for NS previously by others. ${ }^{3}$

Newborns with seizures, whether term or preterm, are at increased risk of unfavorable comorbidities such as neurodevelopmental disorders, cerebral palsy, epilepsy syndrome, and even death. ${ }^{4-6}$ The subsequent development of mental retardation and cerebral palsy has associated with epilepsy in $85 \%$ of cases with previous episodes of NS. ${ }^{6}$ Thus, there should be precise attention to both comorbidities, NSs, and epilepsy. The association between these two need to be precise. Despite the underlying etiologies for NS, it plays a significant role in the unwanted sequels of the newborn's brain, especially those are relating to the mental and cognitive ability of the developing brain. Reports reveal the wide range of results from $1.8 \%$ to $41.3 \%$ on epilepsy incidence rate following an NS episode which may be explained by diversity in their sample size, inclusion criteria, diagnosis methods, and follow-up years. ${ }^{78}$ Here a brief review of the latest studies was provided on the relationship between NSs and epilepsy in newborns and discuss risk factors may contribute to this relationship.

\section{Methods}

A review of the literature was conducted using Google Scholar, PubMed, Web of Science and Google search engine by keywords "neonatal seizure AND epilepsy," "newborns AND epilepsy," "postneonatal epilepsy" then the most relevant human-based studies, published between January 2009 and January 2019, were reviewed. Articles with any languages other than English excluded as well as conference abstracts, case reports, letters,

(C) 2019 The Author(s). This is an open access article distributed under the terms of the Creative Commons Attribution License (http:// creativecommons.org/licenses/by/4.0/), which permits unrestricted use, distribution, and reproduction in any medium, provided the original work is properly cited. 
and reviews. Also, the review process was limited to those studies in which the relationship between NS and afterward, epilepsy has investigated, and the incidence rate and risk factors were determined. The data harvested from each study then was listed in several columns such as year of study, first author's name, duration of the study, study methods, number of patients, diagnosis methods, follow-up duration, and other evaluated variants. the epilepsy incidence rate was measured by dividing the number of all cases of epilepsy who had a history of NS in selected studies considered with the number of all newborns enrolled to the studies minus the number of cases who lost the follow-ups.

\section{Results}

By reviewing the literature, 13 studies were found, which meet the inclusion criteria entirely and published between 2009 and 2019, of which three were population-based while the remaining studies performed hospital-based (Table 1). The diagnosis of NS in 6 studies made based on EEG. In 3 studies this was made through the clinical history and manifestations. The remaining diagnosed with both EEG and clinical methods. All studies, except 3 of them, had included both preterm and term neonates in their investigations. The average number for included NS patients in these studies was more significant than 100 people (129.53). The mean incidence rate for epilepsy after NS was estimated.

Overall, the population evaluated in these series has been estimated to be 2438 newborns of which 454 died, and 300 missed the follow-ups. The incidence rate for afterward epilepsy in all 1684 subjects with NS was 20\%, literally 343 of the NS subjects. The data on the onset age of epilepsy reported by several studies (data not shown).

\section{Discussion}

There is always an increased risk for neurological sequels after an episode of the NSs. Here in this review, epilepsy was focused as one major complication among these sequels. Data from different studies support the epileptogenic effects of NSs on developing brain. ${ }^{17}$ Also, the incidence rate for afterward epilepsy in NS patients based on studies investigated. The reports from the studies included in this review show this rate ranging from 5\% to $35.7 \%$ in compared with other previous populationbased studies in Europe. ${ }^{21}$ The reports indicate that the incidence rate for afterward epilepsy in full-term newborns is higher than in preterm population could thus be due to the more survival of full-term infants than the latter and also a different level of brain development with effects on the electrical discharges initiators and the way they will sustain. ${ }^{22-24}$ They also showed higher rates in clinically-diagnosed NS patients than the EEG-confirmed group..$^{25,26}$

Nevertheless, none of them truly investigate why the outcomes are different in the manner of the method of the diagnosis. Indeed, the diagnosis based on clinical manifestations would be led to over or underestimation by the sudden or purposeless body movements which are false for diagnosis. This is while the electricalonly seizures without any clinical symptoms which are common in high-risk neonates might miss. So, high

Table 1. Data Harvested From Reviewing of the Selected Studies Regarding the Incidence of Epilepsy Following the Neonatal Seizures

\begin{tabular}{|c|c|c|c|c|c|c|c|}
\hline $\begin{array}{l}\text { Year of } \\
\text { Publication/ } \\
\text { Study }\end{array}$ & First Author & $\begin{array}{l}\text { No. of Patients } \\
\text { With NS }\end{array}$ & Study type & $\begin{array}{l}\text { Maximum Follow- } \\
\text { up Duration }\end{array}$ & $\begin{array}{l}\text { Birth Maturity of } \\
\text { Included Patients }\end{array}$ & $\begin{array}{l}\text { Method of } \\
\text { Diagnosis }\end{array}$ & $\begin{array}{l}\text { Incidence } \\
\text { of Epilepsy }\end{array}$ \\
\hline 2009 & Pisani $^{9}$ & $18(1)$ & Retrospective & 2 years & Term and Preterms & EEG & $5.5 \%$ \\
\hline 2010 & Nagarajan ${ }^{10}$ & $52(17)$ & Retrospective & 6 years & Term and Preterms & EEG & $33 \%$ \\
\hline 2010 & Davis ${ }^{11}$ & $414(66)$ & $\begin{array}{c}\text { Retrospective } \\
\text { population-based }\end{array}$ & 22 months & Term and Preterms & Clinical + EEG & $16 \%$ \\
\hline 2011 & Garfinkle $^{12}$ & $120(32)$ & Retrospective & 10 years & Only Term & Clinical + EEG & $27 \%$ \\
\hline 2012 & $\begin{array}{l}\text { Van der } \\
\text { Heide }^{13}\end{array}$ & $82(23)$ & Retrospective & 9 years & Only Term & Clinical + EEG & $29 \%$ \\
\hline 2012 & Pisani $^{6}$ & $85(15)$ & Retrospective & 7 years & Term and Preterms & EEG & $17.6 \%$ \\
\hline 2012 & Yildiz $^{14}$ & $112(40)$ & Retrospective & 44 months & Term and Preterms & Clinical & $35.7 \%$ \\
\hline 2013 & Lai $^{15}$ & $232(53)$ & Retrospective & 3 years & Only Term & Clinical & $23 \%$ \\
\hline 2013 & Sidiq $^{16}$ & $114(23)$ & Retrospective & 2 years & Term and Preterms & Clinical & $20 \%$ \\
\hline 2014 & $\begin{array}{l}\text { Soltirovska- } \\
\text { Salamon }^{17}\end{array}$ & $176(31)$ & Retrospective & At least 2 years & Term and Preterms & Clinical + EEG & $18.1 \%$ \\
\hline 2015 & Suppiej $^{18}$ & $55(9)$ & Prospective & Almost 8 years & Term and Preterms & EEG & $16.4 \%$ \\
\hline 2017 & Pisani ${ }^{19}$ & $112(16)$ & $\begin{array}{c}\text { Retrospective } \\
\text { population-based }\end{array}$ & $\begin{array}{l}\text { Min } 2 \text { years } \\
\text { Max } 15 \text { years }\end{array}$ & Term and Preterms & EEG & $14.3 \%$ \\
\hline 2018 & Andreolli $i^{20}$ & $112(17)$ & $\begin{array}{c}\text { Retrospective } \\
\text { population-based }\end{array}$ & 1.5 years -10 years & Term and Preterms & EEG & $15.2 \%$ \\
\hline
\end{tabular}


variability in the findings of such studies was seen. On the contrary, the studies focused on EEG-based diagnosis might not detect subtle seizures in which there are no detectable EEG changes. However, some authors prefer to consider the only EEG-confirmed NS (suggested by the ILAE) since, as mentioned, this could lead to false diagnosis. In this regard, some believe that sequential video EEG monitoring has a better predictive value so that there is a much stronger correlate between different neurodevelopmental complications.

Another point is that most studies calculating the frequency of NS are hospital-based and the few were population-based cohorts, yet the epidemiology of NS is not well defined.

The results from a study indicate the effect of the duration of NS as a potent predictor factor for afterward epilepsy seems to change widely upon newborn's gestational age. ${ }^{17}$

Epilepsy, based on multiple studies, can occur very early in life during the neonatal period as it estimated to be $26.9 \%-60 \%$ of cases. ${ }^{26,27}$ Several studies reported the average age at onset of $26 \%$ for the neonatal period while 68.5 percent of the onset was within the first year of the infancy, and the onset after the first year of life was estimated to be 35.8 by other studies. ${ }^{6,22,28}$ Also, the development of epilepsy can occur with 5 to 20 months of age delay, as a brief latent period which was noted by a group of researchers before. ${ }^{29}$ Several studies have reported interictal epileptiform abnormalities causing postneonatal epilepsy on EEG-recording. This may raise the probability of the development of late-onset epilepsy. ${ }^{30,31}$ However, the progress of epilepsy during childhood and early adolescence has not adequately addressed because of the limited follow-up available in the majority of the studies. The patient selection methods have been limited to those children with obvious neurodevelopmental disability so that findings of such studies are limited too.

Soltirovska-Salamon et al, ${ }^{17}$ in a bivariate analysis, showed that $18.1 \%$ of cases with the previous history of NS developed epilepsy which was similar to other retrospective cohort studies in where they employ both clinical and EEG-based definitions for NS.

A recent population-based study $y^{20}$ enrolled all neonates with the history of NS who developed epilepsy by the time of the study in Italy. The epilepsy incidence measured by the authors was of $15.2 \%$. The variability mentioned above for the epilepsy incidence explained by multiple factors such as study design, inclusion criteria (enrolling term or preterms), diagnosis methods of seizures, and followup length. From the research, the most comprehensive review on the incidence of epilepsy after NS has reported this rate of $17.9 \%$ by the year 2015 . Their data, same as what we harvested from the review of the literature, were amassed from few population-based studies. ${ }^{23,32}$

The epilepsy incidence rate after NS measured by Davis et $\mathrm{a}^{11}$ has been reported of $16 \%$ where they collected the data through a retrospective study and detected all the cases in both clinical or EEG-confirmed manner but just in deficient birth weight infants only. A retrospective study with a 10-years follow-up at a single center practice found a $27 \%$ incidence in newborns with clinically and non-clinically detected NS.

Another study, evaluating prognostic factors for afterward epilepsy in newborns with NS, followed up the cases for two years and reported the epilepsy incidence rate of $20 \% .{ }^{16}$ Using a multivariate analysis, they also stated that preterm labor does not increase the probability of epilepsy in NS newborns, consistent with other reports. ${ }^{12,31,33}$

In conclusion, the presented review enrolled the most recent studies encompassing enough and extended time as well as adequate sample size. Epilepsy is considered a common outcome of NS, particularly in those with other neurodevelopmental comorbidities, even if there were always several limits associated with various study designs and condition. Besides, these patients are at increased risk of developing epilepsy, especially at a younger age and commonly in the first year of their life. Of note, a cautious interpretation of the finding is important especially when the different fundamental etiological factors linked to NS are not considered, as there are a few population-based studies regarding precise correlation between NS and its later complication. ${ }^{11,23,34}$

\section{Conflict of Interest Disclosures}

The authors declare that they have no conflict of interests.

\section{Ethical Statement}

Not applicable.

\section{Acknowledgements}

We appreciate Dr Farnoosh Ardiyani for her time and kind attention that she gave to our study.

\section{References}

1. Spagnoli C, Pisani F. The independent role of neonatal seizures in epilepsy and other long-term neurological outcomes. Dev Med Child Neurol. 2019;61(6):624. doi: 10.1111/dmcn.14197.

2. Painter MJ, Gaus LM. Neonatal seizures: diagnosis and treatment. J Child Neurol. 1991;6(2):101-8. doi: 10.1177/088307389100600202.

3. Chapman KE, Raol YH, Brooks-Kayal A. Neonatal seizures: controversies and challenges in translating new therapies from the lab to the isolette. Eur J Neurosci. 2012;35(12):185765. doi: 10.1111/j.1460-9568.2012.08140.x.

4. Tekgul H, Gauvreau K, Soul J, Murphy L, Robertson R, Stewart $\mathrm{J}$, et al. The current etiologic profile and neurodevelopmental outcome of seizures in term newborn infants. Pediatrics. 2006;117(4):1270-80. doi: 10.1542/peds.2005-1178.

5. Bureau M, Genton P, Dravet C. Epileptic syndromes in infancy, childhood and adolescence. John Libbey Eurotext; 2012. 
6. Pisani F, Piccolo B, Cantalupo G, Copioli C, Fusco C, Pelosi A, et al. Neonatal seizures and postneonatal epilepsy: a 7-y follow-up study. Pediatr Res. 2012;72(2):186-93. doi: 10.1038/pr.2012.66

7. Connell J, Oozeer R, de Vries L, Dubowitz LM, Dubowitz V. Continuous EEG monitoring of neonatal seizures: diagnostic and prognostic considerations. Arch Dis Child. 1989;64(4 Spec No):452-8. doi: 10.1136/adc.64.4_spec_no.452.

8. Khan RL, Nunes ML, Garcias da Silva LF, da Costa JC. Predictive value of sequential electroencephalogram (EEG) in neonates with seizures and its relation to neurological outcome. J Child Neurol. 2008;23(2):144-50. doi: 10.1177/0883073807308711.

9. Pisani F, Orsini M, Braibanti S, Copioli C, Sisti L, Turco EC. Development of epilepsy in newborns with moderate hypoxicischemic encephalopathy and neonatal seizures. Brain Dev. 2009;31(1):64-8. doi: 10.1016/j.braindev.2008.04.001.

10. Nagarajan L, Palumbo L, Ghosh S. Neurodevelopmental outcomes in neonates with seizures: a numerical score of background encephalography to help prognosticate. J Child Neurol. 2010;25(8):961-8. doi: 10.1177/0883073809355825.

11. Davis AS, Hintz SR, Van Meurs KP, Li L, Das A, Stoll BJ, et al. Seizures in extremely low birth weight infants are associated with adverse outcome. J Pediatr. 2010;157(5):720-5.e1-2. doi: 10.1016/j.jpeds.2010.04.065

12. Garfinkle J, Shevell MI. Cerebral palsy, developmental delay, and epilepsy after neonatal seizures. Pediatr Neurol. 2011;44(2):88-96. doi: 10.1016/j.pediatrneurol.2010.09.001.

13. van der Heide MJ, Roze E, van der Veere CN, Ter Horst HJ, Brouwer OF, Bos AF. Long-term neurological outcome of termborn children treated with two or more anti-epileptic drugs during the neonatal period. Early Hum Dev. 2012;88(1):33-8. doi: 10.1016/j.earlhumdev.2011.06.012.

14. Yildiz EP, Tatli B, Ekici B, Eraslan E, Aydinli N, Caliskan M, et al. Evaluation of etiologic and prognostic factors in neonatal convulsions. Pediatr Neurol. 2012;47(3):186-92. doi: 10.1016/j.pediatrneurol.2012.05.015.

15. Lai YH, Ho CS, Chiu NC, Tseng CF, Huang YL. Prognostic factors of developmental outcome in neonatal seizures in term infants. Pediatr Neonatol. 2013;54(3):166-72. doi: 10.1016/j.pedneo.2013.01.001.

16. Sidiq B, Herini ES, Wibowo T. 2013. Prognostic factors of epilepsy in patients with neonatal seizures history. Paediatr Indones. 2013;53(4):218-22. doi: 10.14238/pi53.4.2013.1822.

17. Soltirovska-Salamon A, Neubauer D, Petrovcic A, ParoPanjan D. Risk factors and scoring system as a prognostic tool for epilepsy after neonatal seizures. Pediatr Neurol. 2014;50(1):77-84. doi: 10.1016/j.pediatrneurol.2013.08.010.

18. Suppiej A, Mastrangelo M, Mastella L, Accorsi P, Grazian L, Casara G, et al. Pediatric epilepsy following neonatal seizures symptomatic of stroke. Brain Dev. 2016;38(1):27-31. doi: 10.1016/j.braindev.2015.05.010.

19. Pisani F, Facini C, Bianchi E, Giussani G, Piccolo B, Beghi E. Incidence of neonatal seizures, perinatal risk factors for epilepsy and mortality after neonatal seizures in the province of Parma, Italy. Epilepsia. 2018;59(9):1764-73. doi: 10.1111/ epi.14537.

20. Andreolli A, Turco EC, Pedrazzi G, Beghi E, Pisani F. Incidence of Epilepsy after Neonatal Seizures: A PopulationBased Study. Neuroepidemiology. 2019;52(3-4):144-51. doi: 10.1159/000494702.

21. Forsgren L, Beghi E, Oun A, Sillanpaa M. The epidemiology of epilepsy in Europe - a systematic review. Eur J Neurol. 2005;12(4):245-53. doi: 10.1111/j.1468-1331.2004.00992.x.

22. Dennis J. Neonatal convulsions: aetiology, late neonatal status and long-term outcome. Dev Med Child Neurol. 1978;20(2):143-8.

23. Holden KR, Mellits ED, Freeman JM. Neonatal seizures. I. Correlation of prenatal and perinatal events with outcomes. Pediatrics. 1982;70(2):165-76.

24. Scher MS, Aso K, Beggarly ME, Hamid MY, Steppe DA, Painter MJ. Electrographic seizures in preterm and full-term neonates: clinical correlates, associated brain lesions, and risk for neurologic sequelae. Pediatrics. 1993;91(1):128-34.

25. Hellstrom-Westas L, Blennow G, Lindroth $M$, Rosen I, Svenningsen NW. Low risk of seizure recurrence after early withdrawal of antiepileptic treatment in the neonatal period. Arch Dis Child Fetal Neonatal Ed. 1995;72(2):F97-101. doi: 10.1136/fn.72.2.f97.

26. Toet MC, Groenendaal F, Osredkar D, van Huffelen AC, de Vries LS. Postneonatal epilepsy following amplitudeintegrated EEG-detected neonatal seizures. Pediatr Neurol. 2005;32(4):241-7. doi: 10.1016/j.pediatrneurol.2004.11.005.

27. Bergman I, Painter MJ, Hirsch RP, Crumrine PK, David R. Outcome in neonates with convulsions treated in an intensive care unit. Ann Neurol. 1983;14(6):642-7. doi: 10.1002/ ana.410140607.

28. Burke JB. The prognostic significance of neonatal convulsions. Arch Dis Child. 1954;29(146):342-5. doi: 10.1136/ adc.29.146.342.

29. Schulte FJ. Neonatal convulsions and their relation to epilepsy in early childhood. Dev Med Child Neurol. 1966;8(4):38192. doi: 10.1111/j.1469-8749.1966.tb01771.x.

30. Gherpelli JLD, Paz JA, Leone CR, Ramos JLA, Diament AJ. Seizure recurrence in infants with neonatal convulsions a follow-up study: estudo evolutivo. Arq Neuropsiquiatr. 1992;50(1):31-6. doi: 10.1590/S0004-282X1992000100006.

31. Nunes ML, Martins MP, Barea BM, Wainberg RC, Costa JC. Neurological outcome of newborns with neonatal seizures: a cohort study in a tertiary university hospital. Arq Neuropsiquiatr. 2008;66(2a):168-74.

32. Minchom P, Niswander K, Chalmers I, Dauncey $M$, Newcombe R, Elbourne D, et al. Antecedents and outcome of very early neonatal seizures in infants born at or after term. $\mathrm{Br}$ J Obstet Gynaecol. 1987;94(5):431-9.

33. Garcias Da Silva LF, Nunes ML, Da Costa JC. Risk factors for developing epilepsy after neonatal seizures. Pediatr Neurol. 2004;30(4):271-7. doi: 10.1016/j.pediatrneurol.2003.09.015.

34. Ronen GM, Buckley D, Penney S, Streiner DL. Long-term prognosis in children with neonatal seizures: a populationbased study. Neurology. 2007;69(19):1816-22. doi: 10.1212/01.wnl.0000279335.85797.2c. 